\title{
Acute otitis media in an infant complicated with osteoarthritis of temporomandibular joint and sub-periosteal abscess of the clavicle
}

\author{
Kaoutar Cherrabi ${ }^{1 *}$ (D) and Hind Cherrabi ${ }^{2}$ (D)
}

\begin{abstract}
Background: Otomastoiditis is a very frequent affection and a current complication of mal-treated benign ear infections in children. However, this a very rare case of the association of two rare complications of otomastoiditis in a newborn.

On the one hand, septic arthritis of the temporomandibular joint which is a very rare condition that is difficult to diagnose, and when unrecognized or not treated accordingly, it can resolve in serious infectious complication and or definitive injury to the temporomandibular joint.

On the other hand, osteomyelitis of the clavicle is also very rare, and only a few cases have been cited in the literature concerning infants.

Case presentation: This 46-day-old infant was brought to pediatric emergency consultation for 2 swelling inflammatory bulges, one in the right mastoid and pre-auricular regions, and another in the right basi-cervical area. The infant was hypertrophic febrile, hypotonic, and pale. He had preserved archaic reflexes. Besides, blood test showed an inflammatory syndrome, inflammatory anemia, and no other abnormalities.

Upon supplementary computed tomodensitometry exam, the diagnosis of a combination of septic arthritis of the right temporomandibular joint and sub-periosteal abscess of the ipsilateral clavicle in a context of hypotrophy and malnutrition was suspected. A pus sample was obtained for bacteriological evaluation, after which the infant had a course of intravenous associated antibiotics, along with nutritional assessment and management. Surgical drainage of both collections was performed. The 6-month follow-up was satisfactory, without clinical signs of functional impact on temporomandibular joint, or acromioclavicular joint.
\end{abstract}

Conclusion: This work stresses the necessity of thorough clinical examination of infants even in cases of benign ear infections, as well as the importance of adapted treatment and follow-up, which could allow early diagnosis, appropriate treatment, or even prevention of severe complications that can be associated with such benign conditions.

Keywords: Acute otitis media, Mastoiditis, Arthritis, Infectious, Temporomandibular joint, Infant newborn, Periosteum, Abscess, Clavicle

\footnotetext{
* Correspondence: kaoutarcherrabi.bz@gmail.com

'ENT and Cervico-facial Department, Hassan II University Hospital, Fez,

Morocco

Full list of author information is available at the end of the article
}

\section{Springer Open}

(c) The Author(s). 2021 Open Access This article is licensed under a Creative Commons Attribution 4.0 International License, which permits use, sharing, adaptation, distribution and reproduction in any medium or format, as long as you give appropriate credit to the original author(s) and the source, provide a link to the Creative Commons licence, and indicate if changes were made. The images or other third party material in this article are included in the article's Creative Commons licence, unless indicated otherwise in a credit line to the material. If material is not included in the article's Creative Commons licence and your intended use is not permitted by statutory regulation or exceeds the permitted use, you will need to obtain permission directly from the copyright holder. To view a copy of this licence, visit http://creativecommons.org/licenses/by/4.0/. 


\section{Background}

Acute otitis media is the most frequent pediatric infectious disease, $80 \%$ of children under 3 years old have had at least one episode [1, 2].Otomastoidis is a very common complication of untreated or maltreated ear infections in children [3]. Several complications of acute otitis media have been cited in the international literature.

This case is a presentation of two rare complications of acute otitis media: aseptic arthritis and osteomyelitis of the clavicle.

\section{Case presentation}

A 46-day-old infant admitted in a pediatric emergency room by a gravida 2 para 2 mother (G2P2) whose medical follow-up at a health center during pregnancy was without incidence, and medical delivery was followed with good adaptation to extrauterine life and exclusive breastfeeding.

At 46 days old, the infant presented with a thick yellowish pus discharge through the external ear canal for 1 day, treated traditionally, with the development after a week of a painful non-inflammatory bulge in the mastoid region, pre-tragic swelling, and another inflammatory swelling next to the right clavicle extending to the cervical region (Fig. 1), which was gradually increasing in size and about $5 \mathrm{~cm}$ in the last week.

No particular history of immune depression or diabetes in the mother's history or any case of severe infection in his brother's history. No other abnormalities have been noted.

No history of surgery and no medical treatment taken.

The general examination found a febrile, pale, hypotonic infant who weighed $2 \mathrm{~kg}$ and $700 \mathrm{mg}$, and the infant had preserved sucking reflex. The infant presented a severe trismus $(15 \mathrm{~mm})$, an inflammatory swelling in the mastoid, pre-auricular regions, and otoscopic exam, after aspiration of $10 \mathrm{ml}$ of pus, found an inflammatory external auditory meatus, and a central tympanic perforation,

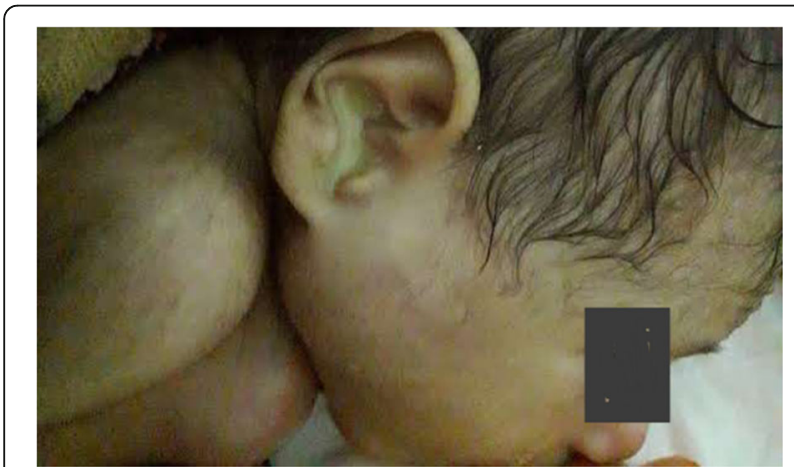

Fig. 1 Pre-operative picture showing inflammatory swelling in the supra-clavicular region with extension to the adjacent cervical region without lesions to ossicles. The second swelling in regard to the right clavicle was inflammatory, and the mobilization of the right arm was painful, without limitation in movements. The rest of the clinical exam was unremarkable.

The patient was treated with traditional preparation and frequent cleaning of auditory meatus, without medical consultation.

The biological assessment showed inflammatory anemia with a biological inflammatory syndrome. A bacteriological sample of pus found at the external auditory canal was taken, and then, he received intravenous biantibiotic therapy and analgesia.

Radiological assessment was carried out through ultrasound of the facial and cervical soft parts in a bilateral comparative manner as well as the collection facing the right clavicle, with the supplementary facial and cervicothoracic computed tomographic exam.

On the facial region, the ultra-sound examination found a heterogeneous collection of hyperechoic content, with an irregular aspect of the temporomandibular joint with infra-temporal microcalcification. And in the subclavicular region, there was an irregular appearance of the bone of the right clavicle, in particular on its internal side, suggesting a purulent sub-periosteal collection.

After an initial percutaneous puncture, the patient was put on broad-spectrum antibiotics.

Supplementary facial and cervico-thoracic computed tomographic exam confirmed the presence of osteolytic lesions of the right temporomandibular joint, with some infra-temporal collections not exceeding 5 - $\mathrm{mm}$ long axis each, with soft tissue infiltration (Figs. 2, 3, and 4).

No challenges in accessing diagnostic tests were found.

Diagnosis of septic arthritis of TMJ, associated with sub-periosteal abscess if clavicle was retained, after elimination of malignant etiologies and other lytic lesions upon clinical, radiological, and biological findings, as well as medical history details.

The infection was considered systemic because of multiple localizations.

Combined medical and surgical management was chosen as the therapeutic approach.

Medical treatment consisted of broad-spectrum antibiotics, then adjusted to bacteriology, and second level analgesics, whilst surgical treatment consisted of percutaneous puncture and drainage of right clavicular collections, and articular puncture and drainage of TMJ. Both residual cavities were washed with betadine serum, and the pus sample was also delivered for bacteriological study.

Bacteriological results for the two samples found staphylococcus aureus. And the antibiotic treatment was changed to a course of anti-staphylococcal drugs. 


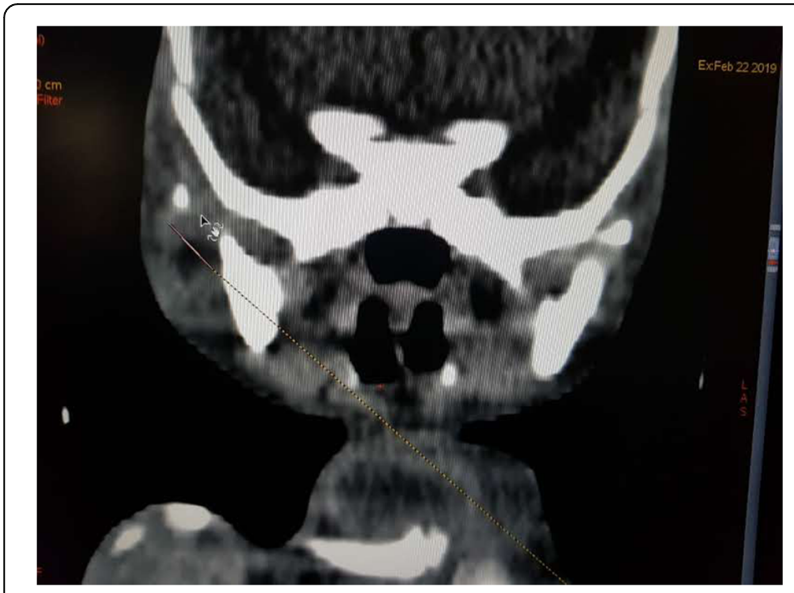

Fig. 2 Computed tomography section showing the temporomandibular joint with osteolytic lesion of the mandibular condyle and the mandibular fossa

The evolution after daily dressing change was favorable.

A 6-month follow-up showed no clinical symptom of injury to the temporomandibular and acromioclavicular joints, with normal weight curves and an absence of clinical symptoms of malnutrition.

Adherence to follow-up was noticeable.

No adverse events were noted.

\section{Discussion}

\section{Introduction}

Several complications of acute otitis media have been cited in the international literature, sub-periosteal collections, facial paralysis, serous or suppurative labyrinthitis, sigmoid sinus thrombosis, epidural or intracranial abscess, petrous apicitus, and otitic hydrocephalitis. Osteoarticular infections in children were very redoubtable

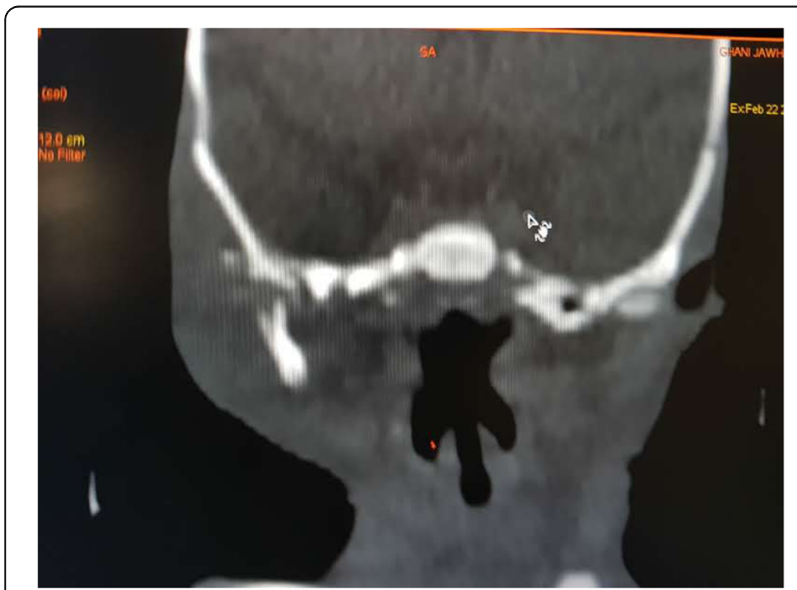

Fig. 3 Computed tomography section showing hydric collection, in temporo-mandibular region

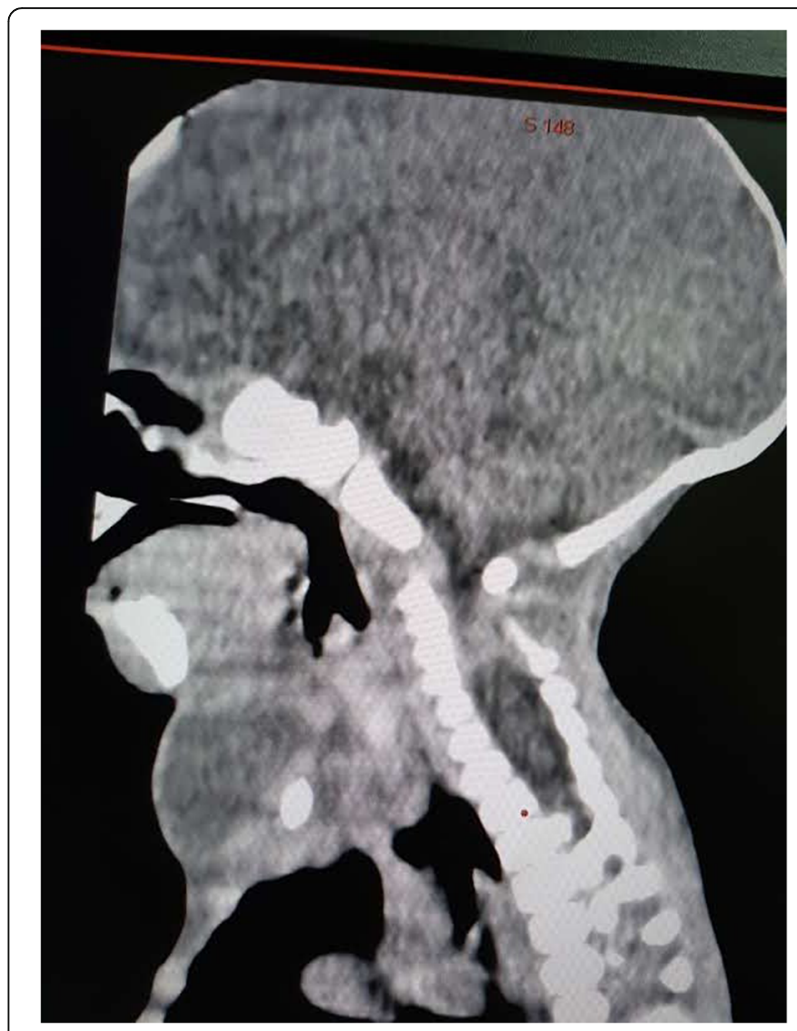

Fig. 4 Computed tomography sagittal sections, showing right preclavicular collection, with extension to latero-central region, with heterogeneous and hypodense content

conditions before the discovery of antibiotics [4].On the one hand, septic arthritis of the temporomandibular joint is a rare complication of acute otitis media $[1,5]$. It is a medical emergency which could have serious infectious and functional sequellae [6].On the other hand, clavicular osteomyelitis is generally caused by hematogenous dissemination coming from an infectious gateway, which is sometimes occult [1, 5]. Moreover, combined osteoarticular infections and osteomyelitis tend to be more serious in children, regarding clinical presentation, biological markers of infection, and the presence of sequellae, and necessity of longer courses of treatment [4]. This case presents the association of two very rare and severe complications of acute otitis media, treated efficaciously with a good outcome.

The main etiology of osteomyelitis and osteo-articular bacterial infection in children and neonates is hematogenous due to high vascularization of the metaphysis in this age group, and the second etiology cited is traumatic events $[1,4,6]$.

Monslave et al. have found that septic arthritis in children is frequently concurrent with osteomyelitis in the same joint, and the risk factors for concurrent septic arthritis and osteomyelitis were age group (newborn or adolescents), shoulder joint involved, symptoms for 
more than 6 days, and infection by staphylococcus (both methicillin-sensitive and resistant) [7].

There are rare cases of bacterial arthritis of the temporomandibular joint in the literature. It has a very heterogeneous and non-specific clinical aspect, which makes the diagnosis difficult. Most cases of temporomandibular joint septic arthritis are adults, and 40 cases in the Japanese literature only counted 3 children and 30 adults in the English literature [8].

There are no unified diagnostic criteria for TMJ septic arthritis in the literature [8]. The signs that are found are mostly fever and signs of inflammation-edema, erythema, and pain in peri-auricular area. The signs of dysfunction are trismus, asymmetry of bite, and posterior subluxation of the mandible $[6,9,10]$.

Early diagnosis and treatment can avoid severe complications [6].

Careful history taking, physical examination, radiographic imaging, laboratory testing, aspiration, and biopsy are all important tools to establish a positive diagnosis and eliminate differential diagnosis in septic arthritis of TMJ $[6,10]$.

Needle aspiration has both diagnostic and therapeutic relevance, by providing bacteriological diagnostic confirmation and decompression of TMJ articulation [9].

The signs of osteomyelitis of the clavicle are inflammatory signs: redness, swelling, intense pain upon pressure, and inflammation may extend to supra-clavicular fossa and cause torticollis [11]. Sub-periosteal collection is a frequent complication of osteomyelitis, and it is an indication for surgical management. Multi-focal osteomyelitis can occur at any age, and it is more seen in neonates [12].

Early signs of septic arthritis of TMJ can sometimes be interpreted as signs of dysfunction of TMJ: osteoarthritis and inflammatory arthritis such as rheumatoid arthritis and retro discitis (SW Yong), vascularitis, crystal associated arthritis, drug-induced arthritis, and reactive arthritis [13].

Differential diagnoses of osteomyelitis of clavicle are generally infectious diseases such as cellulitis of soft tissue, malign tumors especially Ewing's sarcoma, neuroblastoma and osteosarcoma, and benign tumors like osteomas and osteoblastoma, histiocytosis, and vascular lesions giving osteonecrosis, as well as bone fractures and traumatic lesions $[11,12]$.

Ultrasound was cited as a radiological asset in order to guide needle aspiration [14].CT scan and contrast enhanced CT scan and MRI allow the discovery of joint effusion, changes in articulation surfaces, ankyloses, and osteomyelitis of TMJ [6].MRI is an interesting tool to diagnose osteomyelitis associated with septic arthritis [7].

Most important biological findings are CRP, WBC, and ESR, and an important increase in biological inflammatory syndrome is correlated with severity and prognosis of septic arthritis of TMJ [6].

Examination of articular liquid is achieved by considering its macroscopic aspect and its cellular content [6].

Germs that are mostly found in septic arthritis of TMJ are Staphylococcus aureus, Neisseria gonorrhoeae, Haemophilus influenza, and Streptococcus [6] (Pseudomonas aeroginosa and Escherichia coli) [13]. Cai et al. reported for the first time Staphylococcus saprophyticus as a pathogen responsible for septic arthritis for TMJ [8].

Medical treatment consists on broad-spectrum antibiotics, rearranged after antibiogram $[1-3,6,8,11]$. There is no consensus for treatment of septic arthritis of TMJ in the literature $[8,10]$. Different strategies are possible: needle aspiration, arthroscopy, and arthrotomy [10].

Several complications of septic arthritis have been cited in the literature: Zygomatitis, Gradenido's syndrome, sinus thrombosis, otogenic meningitis, labyrinthitis, facial paralysis, intracerebral and neck abscesses, and distruction of the TMJ articulation [10].

Septic arthritis of TMJ is considered as a serious infection considering the recurrence of functional sequelae in infants and children in general [11]. Whilst the severity of clavicular osteomyelitis resides in its anatomical particularity, because vascularization of the clavicle is generally lateral, trauma and compression may result in interruption of vascularization and necrosis [11].

Septic arthritis of TMJ is related to a mortality rate as great as $12 \%$, and the survivors have a $75 \%$ risk of functional problems of TMJ [8].

Complications of septic arthritis of TMJ are infectious, functional, and esthetic, including ankyloses of TMJ, osteomyelitis, and facial asymmetry $[9,10,15]$.

Among pediatric patients, facial asymmetry due to deficient mandibular growth caused by injury to the growth plate under the fibrocartilage covering the condylar head is a redoubtable complication [15].

The association of two severe osteo-articular and osseous infections is very rarely treated without sequellae, especially affecting the growth and function of articulation. Clinical, biological, and radiological aspects guide diagnostic decisions, and the bacteriological results confirm the final diagnosis.

\section{Conclusion}

This work presents the rare association of two rare osteoarticular infections complicating acute otitis media in an infant, and medical treatment associated with surgery has allowed a complete recovery. Moreover, this case underlines the importance of thorough clinical examination of infants, and precocious proper medical management, in order to prevent such severe complications.

The parents were satisfied with the result of management and understood the importance of medical 
consultations for pathological events, instead of traditional remedies.

Parents' consent was obtained after explaining the prognosis and steps of management.

\section{Abbreviations}

G2P2: Gravida 2 para 2 mother pregnancy; TMJ: Temporomandibular joint: CRP: C-reactive protein; CT: Computed tomodensitometry; MRI: Magneticresonance imagery; WBC: White blood count; ESR: Erythrocyte sedimentation rate

\section{Acknowledgements}

Not applicable.

\section{Authors' contributions}

KC: conceived and designed the analysis, collected the data, performed the analysis and wrote the paper. HC: collected the data and contributed data or analysis tools. All authors have read and agreed to its content.

\section{Funding}

None.

Availability of data and materials

Not applicable.

\section{Declarations}

Ethics approval and consent to participate

Not applicable.

\section{Consent for publication}

Written informed consent to publish has been obtained from the parent of patient.

\section{Competing interests}

The authors declare that they have no competing interests.

\section{Author details}

${ }^{1}$ ENT and Cervico-facial Department, Hassan II University Hospital, Fez, Morocco. ${ }^{2}$ Pediatric Surgery Department, Mohamed V Hospital, Al Houceima, Morocco.

Received: 9 December 2020 Accepted: 21 May 2021

Published online: 19 June 2021

\section{References}

1. Castellazzi ML, Senatore L, Di Pietro G et al (2019) Otogenic temporomandibular septic arthritis in a child: a case report and a review of the literature. Ital J Pediatr 45:88. https://doi.org/10.1186/s13052-019-0682-2

2. Castellazzi L, Mantero M, Esposito S (2016) Update on the management of pediatric acute osteomyelitis and septic arthritis. Int J Mol Sci 17(6): 855Published 2016 Jun 1. https://doi.org/10.3390/ijms17060855

3. Goldstein NA, Casselbrant ML, Bluestone CD, Marcia K-L, Pittsburgh P (1998) Intratemporal complications of acute otitis media in infants and children. Otolaryngol Head Neck Surg 119(5):444-454. https://doi.org/10.1016/S01945998(98)70100-7

4. Arnold JC, Bradley JS (2015) Osteoarticular infections in children. Infect Dis Clin N Am 29(3):557-574. https://doi.org/10.1016/j.idc.2015.05.012 PMID: 26311358

5. Mattos JL, Colman KL, Casselbrant ML, Chi DH (2014) Intratemporal and intracranial complications of acute otitis media in a pediatric population. Int J Pediatr Otorhinolaryngol 78(12):2161-2164. https://doi.org/10.1016/j.jporl.2 014.09.032

6. Yang SW, Cho JY, Kim HM (2016) Septic arthritis of the temporomandibular joint: a case report. J Korean Assoc Oral Maxillofac Surg 42(4):227-230. https://doi.org/10.5125/jkaoms.2016.42.4.227

7. Monsalve J, Kan JH, Schallert EK, Bisset GS, Zhang W, Rosenfeld SB (2015) Septic arthritis in children: frequency of coexisting unsuspected osteomyelitis and implications on imaging work-up and management. AJR
Am J Roentgenol 204(6):1289-1295. https://doi.org/10.2214/AJR.14.12891 PMID: 26001240

8. Cai XY, Yang C, Zhang ZY, Qiu WL, Chen MJ, Zhang SY (2010) Septic arthritis of the temporomandibular joint: a retrospective review of 40 cases. J Oral Maxillofac Surg 68(4):731-8. https://doi.org/10.1016/j.joms.2009.07.060

9. Kim B, Choi H-W, Kim J-Y, Park K-H, Huh J-K (2019) Differential diagnosis and treatment of septic arthritis in the temporomandibular joint: a case report and literature review. J Oral Med Pain 44:127-132. https://doi.org/10.14476/ jomp.2019.44.3.127

10. Bast F, Collier S, Chadha P, Collier J (2015) Septic arthritis of the temporomandibular joint as a complication of acute otitis media in a child: a rare case and the importance of real-time PCR for diagnosis. Int J Pediatr Otorhinolaryngol 79(11):1942-1945. https://doi.org/10.1016/.i.jporl.2015.08. 014 Epub 2015 Aug 15. PMID: 26340928

11. Chrysochoou E, Antachopoulos C, Badekas K, Roilides E $(2016,2016)$ A rare case of clavicle osteomyelitis in a child and literature review. Case Rep Pediatrics:1-5. https://doi.org/10.1155/2016/8252318

12. Pääkkönen $\mathrm{M}$, Peltola $\mathrm{H}$ (2012) Management of a child with suspected acute septic arthritis. Arch Dis Child 97(3):287-292. https://doi.org/10.1136/a rchdischild-2011-300462 Epub 2011 Sep 27. PMID: 21953417

13. Al-Khalisy HM, Nikiforov I, Mansoora Q, Goldman J, Cheriyath P (2015) Septic arthritis in the temporomandibular joint. North Am J Med Sci 7:480-482

14. Givon U, Liberman B, Schindler A, Blankstein A, Ganel A (2004) Treatment of septic arthritis of the hip joint by repeated ultrasound-guided aspirations. J Pediatr Orthop 24(3):266-270

15. Frojo G, Tadisina KK, Shetty V, Lin AY (2018) Temporomandibular joint septic arthritis. Plast Reconstr Surg Glob Open 6(1):e1648. https://doi.org/10.1097/ GOX.0000000000001648 PMID: 29464173; PMCID: PMC5811303

\section{Publisher's Note}

Springer Nature remains neutral with regard to jurisdictional claims in published maps and institutional affiliations.

\section{Submit your manuscript to a SpringerOpen ${ }^{\circ}$ journal and benefit from:}

- Convenient online submission

- Rigorous peer review

- Open access: articles freely available online

- High visibility within the field

- Retaining the copyright to your article

Submit your next manuscript at $\boldsymbol{\nabla}$ springeropen.com 